\title{
Caracterização de genótipos de cebola com a utilização de marcadores moleculares RAPD ${ }^{1}$
}

\author{
Characterization of onion genotypes using RAPD molecular markers
}

\author{
Gerson Henrique Wamser², Jefferson Luís Meirelles Coimbra* ${ }^{3 *}$, Altamir Frederico Guidolin ${ }^{3}$, Sérgio Dias \\ Lannes $^{2}$ e Gilberto Luiz Dalagnol ${ }^{4}$
}

\begin{abstract}
RESUMO - A divergência genética foi avaliada entre quinze genótipos de cebola cultivados em Santa Catarina, com a utilização de marcadores moleculares RAPD. Onze oligonucleotídeos iniciadores da série Operon Technologies foram utilizados e produziram 35 marcadores, destes, 28 foram polimórficos. Os produtos da amplificação foram visualizados em gel de agarose 1,4\%, corado com brometo de etídeo. Uma matriz de similaridade utilizando-se o coeficiente de Jaccard foi construída a partir dos dados moleculares. Um dendrograma foi gerado para melhor visualização da similaridade genética através do método de agrupamento UPGMA. Três grupos foram formados utilizando o coeficiente de similaridade 0,6 como ponto de corte. O primeiro grupo reuniu os genótipos Super Superprecoce e Gauchinha. O segundo grupo reuniu doze genótipos. Dentro desse grupo, os genótipos Bella Vista e Bella Dura foram os que apresentaram o maior coeficiente de similaridade, em torno de 0,89. Bela Vista e Superprecoce, Catarina e o híbrido Bella Vista, com coeficiente de similaridade de 0,88 entre os pares. O terceiro grupo apresentou apenas o genótipo Crioula Roxa, que obteve o menor valor $(0,31)$ para o coeficiente de similaridade. Tendo em vista os resultados obtidos, cruzamentos entre os genótipos do primeiro e segundo grupo e destes com o genótipo Crioula Roxa, podem ser melhores por apresentarem maior divergência entre si. A técnica de RAPD mostrou-se eficaz na caracterização molecular dos genótipos de cebola, evidenciando que existe variabilidade entre os genótipos estudados.
\end{abstract}

Palavras-chave: Allium cepa L.. Melhoramento vegetal. Divergência genética.

\begin{abstract}
The genetic divergence has been measure between fifteen genotypes of onion grown in Santa Catarina using RAPD markers. Eleven primers from Operon Technologies series was used to produced 35 markers, these, 28 were polymorphic. The amplification products were visualized on $1.4 \%$ agarose gel stained with ethidium bromide. A similarity matrix using the Jaccard coefficient was constructed with the molecular data. A dendrogram was generated to better visualize the genetic similarity using a clustering method UPGMA. Three groups were formed using the similarity coefficient 0.6 as cutoff point. The first group met genotypes Super Superprecoce and Gauchinha. The second group met twelve genotypes. Into this group, the genotypes Bella Vista and Bella Dura were those with the greatest similarity coefficient, around 0.89. Bela Vista and Superprecoce, Catarina and the hybrid Bella Vista, with similarity coefficient of 0.88 between the pairs. The third group had only the genotype Crioula Roxa, which had the lowest value (0.31) for the similarity coefficient. Given these results, crosses between the genotypes of the first and second group and those with genotype Crioula Roxa can be better, because they have greater divergence between them. The RAPD technique proved effective in the molecular characterization of genotypes of onion, showing that there is variability among the genotypes.
\end{abstract}

Key words: Allium cepa L.. Plant breeding. Genetic divergence.

\footnotetext{
*Autor para correspondência

${ }^{1}$ Recebido para publicação em 06/09/2011; aprovado em 11/03/2014

Pesquisa financiada pela UDESC, CNPq, CAPES e FAPESC; parte da Dissertação de Mestrado do primeiro autor

${ }^{2}$ Empresa de Pesquisa Agropecuária e Extensão Rural de Santa Catarina-Epagri, Estação Experimental de Ituporanga, Ituporanga-SC, Brasil.,gwamser@epagri.sc.gov.br sergiolannes@epagri.sc.gov.br

${ }^{3}$ Instituto de Melhoramento e Genética Molecular, Centro de Ciências Agroveterinárias, Universidade do Estado de Santa Catarina, Av. Luiz de Camões 2090, Conta Dinheiro, Lages-SC, Brasil, 88.520-000, coimbrajefferson@udesc.br; altamirguidolin@gmail.com

${ }^{4}$ Empresa de Pesquisa Agropecuária e Extensão Rural de Santa Catarina- Epagri, Estação Experimental de Lages, Lages-SC, Brasil. gldalagnol@ epagri.sc.gov.br
} 


\section{INTRODUÇÃO}

A cebola, (Allium cepa L.), é uma das plantas cultivadas de mais ampla difusão no mundo, sendo consumida por quase todos os povos do planeta, independente da origem étnica e cultural, constituindo-se em um importante elemento de ocupação da mão-de-obra familiar (BOITEUX; MELO, 2004). A partir de acessos de cebola introduzidos da Europa foram selecionadas as populações Baia Periforme no Rio Grande do Sul e Crioula em Santa Catarina. O grupo Baia Periforme se caracteriza por sua ampla adaptação às condições de cultivo no Brasil, boa tolerância às principais doenças da cultura e boa conservação pós-colheita, já as cultivares do grupo Crioula são mais adaptadas à região Sul, apresentam bulbos de coloração amarelo escuro, ótima conservação pós-colheita e ampla aceitação no mercado (BUZAR; OLIVEIRA; BOITEUX, 2007). Segundo Vilela et al. (2005), uma alternativa sugerida para aumentar a eficiência e a competitividade do agronegócio de cebola brasileiro tem sido diversificar a oferta de cultivares, procurando diferenciar o produto nacional em relação ao oferecido por mercados concorrentes.

Quanto às técnicas de melhoramento podese afirmar que os híbridos são mais uniformes e seu desenvolvimento tem sido uma tendência nos programas de melhoramento, no entanto as cultivares de polinização aberta continuam importantes, pois possuem uma base genética mais ampla que os híbridos, podendo ser melhor adaptadas sob condições adversas (LEITE, 2007).

Visando determinar a similaridade genética em cebola, vários autores têm utilizado descritores morfológicos, moleculares e bioquímicos, como exemplo: Barbieri et al. (2005) com marcadores morfológicos; Buzar, Oliveira e Boiteux (2007) com descritores morfológicos, agronômicos e bioquímicos; Leite e Anthonisen (2009) e Maniruzzaman et al. (2010) com RAPD; Mahajan et al. (2009) e Santos et al. (2010) com microssatélites; Santos et al. (2011) e Phillips et al.(2008) com AFLP.

A tendência atual do melhoramento genético é a utilização e a integração das metodologias tradicionais com as modernas técnicas biotecnológicas (LEITE; ANTHONISEN, 2009). Entre estes, os marcadores isoenzimáticos permitem o uso de um número limitado de loci, enquanto marcadores do tipo RFLP (restriction fragment length polymorphism), AFLP (amplified fragment length polymorphism) e VTNR (variable number of tendem repeats) são caros, laboriosos e geralmente necessitam de marcação radioativa (BORGES et al., 2007). Os marcadores do tipo RAPD superam estas limitações, uma vez que muitos loci podem ser estudados simultaneamente $\mathrm{e}$, associados à possibilidade de utilização de vários iniciadores, garantem a análise de uma amostra significativa de todo o seu genoma (DIAS et al., 2003).
Ou seja, um dos marcadores moleculares mais utilizados é o RAPD, por ser uma técnica rápida e de custo relativamente baixo com razoável potencial informativo (AREIAS et al., 2006).

Sendo assim, o objetivo deste trabalho foi avaliar a divergência genética existente entre genótipos de cebola cultivados no Estado de Santa Catarina utilizando marcadores RAPD.

\section{MATERIAL E MÉTODOS}

Foram avaliados quinze genótipos de cebola (Tabela 1). Para tanto foi extraído o DNA de plantas jovens, cultivadas em casa de vegetação.

As plantas coletadas foram imediatamente liofilizadas e em seguida armazenadas em freezer com temperatura de $-20{ }^{\circ} \mathrm{C}$. O protocolo de extração de DNA utilizado foi o CTAB 2x (FERREIRA; GRATAPAGLIA,1998) com algumas modificações: utilização de 6000 RPM na primeira centrifugação e betamercaptoetanol a 2\%. Após a extração, as amostras de DNA foram observadas em gel de agarose $1 \%$ e a seguir quantificadas em espectrofotômetro. Após a quantificação o DNA foi diluído para uma concentração de $10 \mathrm{ng} \mu \mathrm{l}^{-1} \mathrm{em}$ água estéril e estocado a $-20{ }^{\circ} \mathrm{C}$.

Para as reações de amplificação foram testados 20 iniciadores de 10 bases da série "Operon Technologies", a fim de verificar aqueles que apresentassem amplificação, qualidade e repetibilidade nos testes realizados, sendo que destes foram selecionados onze iniciadores (Tabela 2). As reações de amplificação foram realizadas com um ciclo de 2 minutos a uma temperatura de $94{ }^{\circ} \mathrm{C}$; três ciclos de um minuto a $94{ }^{\circ} \mathrm{C}$; um minuto a $35{ }^{\circ} \mathrm{C}$ e dois minutos a $72{ }^{\circ} \mathrm{C}$ (amplificação dos fragmentos proporcionando menor estringência); 35 ciclos de 1 minuto a $94{ }^{\circ} \mathrm{C}$; 1 minuto a $40{ }^{\circ} \mathrm{C}$ e 2 minutos a $72{ }^{\circ} \mathrm{C}$ (amplificação dos fragmentos com maior estringência); um ciclo com 5 minutos a $72{ }^{\circ} \mathrm{C}$ para a finalização da extensão.

As reações foram preparadas com um volume de $15 \mu \mathrm{L}$ com os seguintes componentes e respectiva concentração: Tampão PCR 1X; $\mathrm{MgCl}$ 2,5 mM; dNTPs 0,25 mM cada nucleotídeo; iniciador 0,4mM; Enzima Taq DNA polimerase $0,5 \mathrm{U}$; solução de DNA $40 \mathrm{ng}$; água qsp. $15 \mu \mathrm{L}$.

A separação dos fragmentos amplificados foi realizada através de eletroforese em gel de agarose na concentração de $1,4 \%$, corado com brometo de etídeo na concentração de $0,15 \mu \mathrm{g} . \mathrm{mL}^{-1}$ de gel e submerso em tampão TBE $1 \mathrm{X}$ (Tris HCl, Ácido Bórico e EDTA). Aplicou-se $6 \mu \mathrm{L}$ da reação juntamente com $1 \mu \mathrm{L}$ de 
tampão de carregamento (azul de bromofenol). A separação foi realizada durante três horas, em cuba de eletroforese com uma tensão de $120 \mathrm{~V}(5,0 \mathrm{~V}$ por centímetro). A eletroforese era encerrada após o tampão de carregamento percorrer $10 \mathrm{~cm}$ no gel, permitindo assim, uma boa separação dos fragmentos. O resultado da eletroforese foi visualizado com o auxílio da luz ultravioleta e em seguida capturado com foto documentador.

A obtenção dos resultados foi através da observação da presença (1) ou ausência (0) de banda de cada marcador de cada primer, constituindo-se assim os dados moleculares

Tabela 1 - Genótipos de cebola avaliados, categoria e origem das sementes

\begin{tabular}{lcc}
\hline Genótipo & Categoria & Origem \\
\hline Empasc 352 - Bola Precoce & População Comercial & Epagri \\
Empasc 355 - Juporanga & População Comercial & Epagri \\
Epagri 362 - Crioula Alto Vale & População Comercial & Epagri \\
Epagri 363 - Superprecoce & População Comercial & Epagri \\
Super Superprecoce & População & Epagri \\
Bela Vista & População & Epagri \\
Baia Indaial & População & Epagri \\
Crioula Roxa & População & Epagri \\
Crioula Branca & População & Epagri \\
Bella Catarina & Híbrido & Sakata \\
Bella Vista & Híbrido & Sakata \\
Bella Dura & Híbrido & Sakata \\
Boreal & População Comercial & Hortec \\
Gauchinha & População Comercial & Hortec \\
Catarina & População Comercial & Agritu \\
\hline
\end{tabular}

Tabela 2 - Seqüência dos oligonucleotídeos iniciadores de 10 bases de seqüência arbitrária (primers) utilizados na reação em cadeia da polimerase

\begin{tabular}{lc}
\hline Iniciador* & Seqüência dos nucleotídeos $\left(5^{\prime}-3^{\prime}\right)$ \\
\hline OPA-01 & CAGGCCCTTC \\
OPA-05 & AGGGGTCTTG \\
OPA-06 & AGGGGTCTTG \\
OPA-07 & GAAACGGGTG \\
OPB-04 & GGACTGGAGT \\
OPB-12 & CCTTGACGCA \\
OPC-04 & CCGCATCTAC \\
OPC-05 & GATGACCGCC \\
OPAM-13 & CACGGCACAA \\
OPR-02 & CACAGCTGCC \\
OPO-16 & TCGGCGGTTC \\
\hline
\end{tabular}

*Nomenclatura dos oligonucleotídeos iniciadores de 10 bases de sequiência arbitrária conforme denominação da Operon Technologies Inc., Alameda CA, USA, 1999 binários. A presença de um marcador em mais de um indivíduo significa que os indivíduos partilham da mesma seqüência nos sítios de hibridização com o primer e que estes sítios são separados pelo mesmo número de pares de bases (BINNECK; NEDEL; DELLAGOSTIN, 2002).

A partir da matriz binária gerada pelo conjunto de bandas observado (Figura 1), foi feita a estimativa das medidas de similaridade utilizando o Coeficiente de Jaccard, que mede a proporção de produtos presentes nos dois perfis de RAPD. $\mathrm{O}$ valor 0 significa nenhuma similaridade, enquanto valores próximos de 1 indicam maior similaridade entre os itens (DIAS, 2006). Em seguida, utilizando a matriz de similaridade e o método de agrupamento UPGMA (Unweighted Pair-Group Method Using Arithmetic Mean), foi elaborado um dendrograma de similaridade entre os genótipos e também realizado o cálculo de correlação cofenética (r), através do programa NTSYS-pc versão 2.1 (ROHLF, 2000). Com o auxílio do programa computacional Winboot (YAP; NELSON, 1996) foi realizada a análise de "bootstraping" com 1.000 reamostragens. 
Figura 1 - Eletroforese em gel de agarose com o Primer OPA-01. 1 a 15 (genótipos de cebola); (-) (amostra controle sem DNA); M (marcador 100pb DNA ladder)

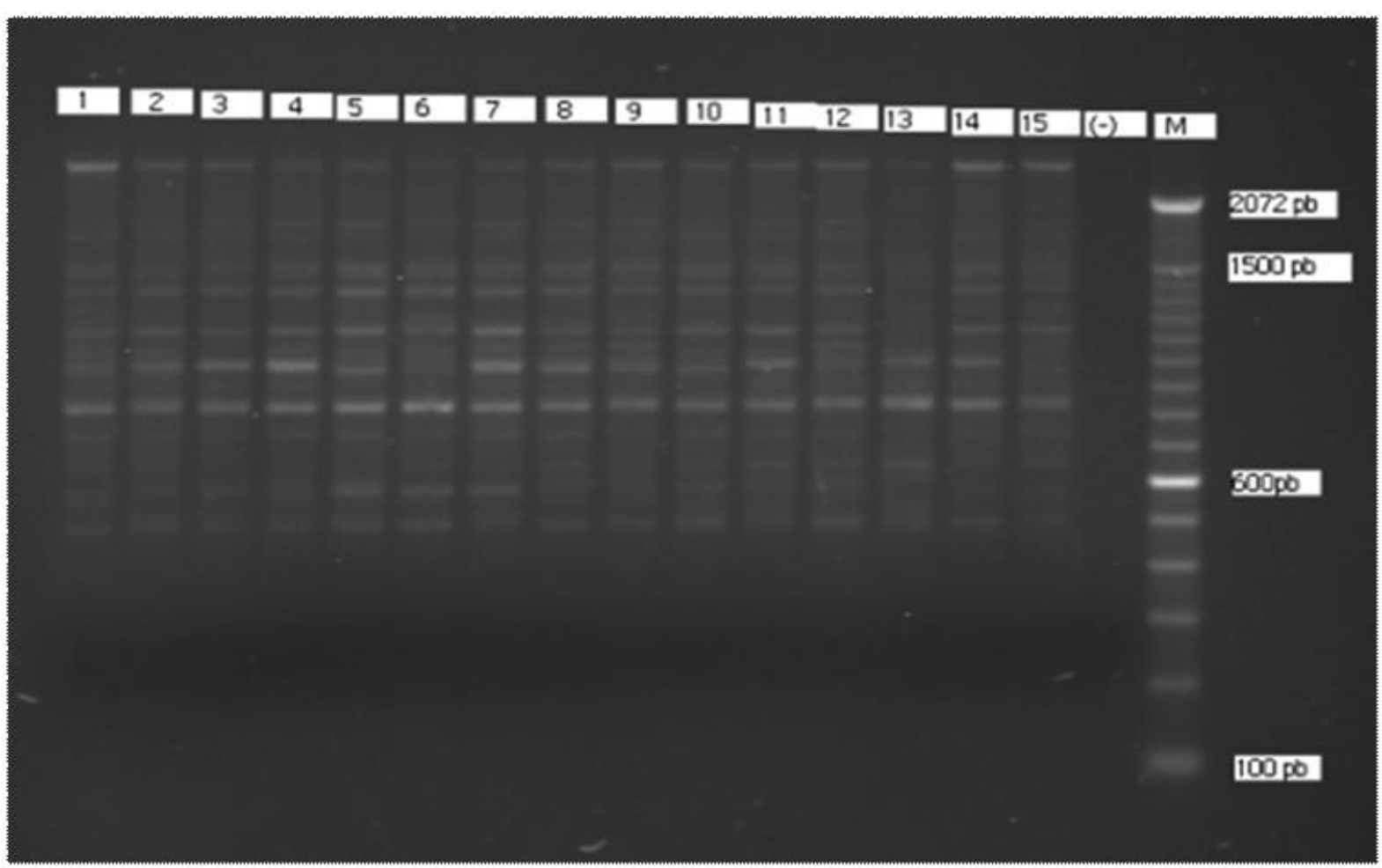

\section{RESULTADOS E DISCUSSÃO}

Os onze iniciadores utilizados geraram 28 bandas polimórficas $(80 \%)$ de um total de 35 bandas, perfazendo 3,18 bandas por iniciador (Tabela 3). Estes valores ficaram abaixo dos encontrados por Leite e Anthonisen (2009) e Maniruzzaman et al. (2010) com 15 e 14 bandas por iniciador respectivamente, ambos em cebola. Por outro lado, Vieira e Nodari (2007), trabalhando com divergência genética em alho obtiveram 5,7 bandas por iniciador e Carvalho (2008) obteve 4,6 bandas por iniciador, trabalhando com a cultura do feijão. Tem sido constatado que o número médio de bandas ou marcadores polimórficos por iniciador é três bandas (RAMALHO; SANTOS; PINTO, 2008). No caso dos marcadores RAPD, uma grande vantagem que existe e que deve ser explorada pelo experimentador, é que muitos marcadores são gerados, o que permite uma flexibilidade para selecionar sempre aqueles mais robustos (FERREIRA; GRATTAPAGLIA, 1998). As diferenças encontradas no número de marcadores podem ser explicadas por Binneck, Nedel e Dellagostin (2002), que sugerem que a competição entre produtos pode gerar bandas distintas e instáveis, tornando-se um reflexo direto do grau da competitividade do sítio e variando com fatores como a complementaridade ao primer e estruturas secundárias no DNA molde. Foram testados os efeitos de vários fatores sobre o padrão de bandas obtidas com marcadores RAPD em A. sexdens rubropilosa, sendo que os fatores mais relevantes para a obtenção de condições ótimas de amplificação dos fragmentos foram o programa de amplificação e a quantidade de DNA (CARVALHO; VIEIRA, 2001).

Analisando os valores dos coeficientes de similaridade de Jaccard (Tabela 4), verifica-se que os maiores valores encontrados foram entre os híbridos Bella Vista e Bella Dura $(0,89)$, entre Superprecoce e Bela Vista e também entre Catarina e Bella Vista $(0,88)$. O menor valor de similaridade foi entre os genótipos Gauchinha e Crioula Roxa $(0,26)$. O coeficiente médio de similaridade de todo o experimento foi de 0,64. Santos et al. (2011) trabalhando com divergência em cebola, encontraram valores superiores a 0,39 . O genótipo Crioula Roxa apresentou o menor coeficiente de similaridade médio, sendo, portanto o mais divergente entre os genótipos estudados.

O dendrograma apresentou $\mathrm{r}=0,82$ como valor de correlação com a matriz de similaridade (Figura 2). Adotando como ponto de corte o coeficiente de similaridade de 0,6 observa-se a formação de três grupos principais. 
Tabela 3 - Oligonucleotídeos iniciadores, número total de bandas, número total de bandas polimórficas e porcentagem de bandas polimórficas

\begin{tabular}{lccc}
\hline Iniciador & $\mathrm{n}^{0}$ total bandas & $\mathrm{n}^{\circ}$ total de bandas polimórficas & \% de bandas polimórficas \\
\hline OPA-01 & 4 & 3 & 75 \\
OPA-05 & 4 & 3 & 75 \\
OPA-06 & 2 & 2 & 100 \\
OPA-07 & 3 & 2 & 66 \\
OPB-04 & 3 & 3 & 100 \\
OPB-12 & 7 & 5 & 71 \\
OPC-04 & 1 & 1 & 100 \\
OPC-05 & 1 & 1 & 100 \\
OPAM-13 & 6 & 4 & 66 \\
OPR-02 & 3 & 3 & 100 \\
OPO-16 & 1 & 1 & 100 \\
Total & 35 & 28 & \\
\hline
\end{tabular}

Tabela 4 - Coeficientes de similaridade de Jaccard de 15 genótipos de cebola obtidos com a utilização de marcadores RAPD

\begin{tabular}{lccccccccccccccc}
\hline$*$ & 1 & 2 & 3 & 4 & 5 & 6 & 7 & 8 & 9 & 10 & 11 & 12 & 13 & 14 & 15 \\
\hline 1 & 1,00 & & & & & & & & & & & & & & \\
2 & 0,71 & 1,00 & & & & & & & & & & & & \\
3 & 0,61 & 0,88 & 1,00 & & & & & & & & & & & \\
4 & 0,53 & 0,68 & 0,78 & 1,00 & & & & & & & & & & \\
5 & 0,48 & 0,70 & 0,70 & 0,70 & 1,00 & & & & & & & & & \\
6 & 0,50 & 0,59 & 0,57 & 0,57 & 0,81 & 1,00 & & & & & & & & & \\
7 & 0,48 & 0,71 & 0,76 & 0,76 & 0,70 & 0,64 & 1,00 & & & & & & & & \\
8 & 0,58 & 0,57 & 0,57 & 0,65 & 0,52 & 0,61 & 0,58 & 1,00 & & & & & & \\
9 & 0,53 & 0,68 & 0,68 & 0,68 & 0,70 & 0,71 & 0,61 & 0,74 & 1,00 & & & & & \\
10 & 0,55 & 0,70 & 0,70 & 0,70 & 0,71 & 0,73 & 0,63 & 0,67 & 0,89 & 1,00 & & & & \\
11 & 0,55 & 0,64 & 0,68 & 0,68 & 0,56 & 0,64 & 0,68 & 0,58 & 0,68 & 0,77 & 1,00 & & & \\
12 & 0,53 & 0,78 & 0,78 & 0,68 & 0,70 & 0,64 & 0,68 & 0,65 & 0,88 & 0,79 & 0,68 & 1,00 & & & \\
13 & 0,28 & 0,30 & 0,30 & 0,37 & 0,27 & 0,30 & 0,35 & 0,35 & 0,37 & 0,33 & 0,29 & 0,30 & 1,00 & & \\
14 & 0,58 & 0,83 & 0,83 & 0,83 & 0,75 & 0,61 & 0,73 & 0,70 & 0,74 & 0,75 & 0,65 & 0,74 & 0,29 & 1,00 & \\
15 & 0,69 & 0,67 & 0,58 & 0,76 & 0,60 & 0,48 & 0,59 & 0,63 & 0,58 & 0,60 & 0,52 & 0,58 & 0,26 & 0,72 & 1,00 \\
\hline
\end{tabular}

*Genótipos: 1- Super Superprecoce; 2- Bela Vista; 3-Epagri 363 Superprecoce; 4-Baia Indaial; 5-Empasc 352 Bola Precoce; 6-Empasc 355 Juporanga; 7-Epagri 362 Crioula Alto Vale; 8-Bella Catarina; 9-Bella Vista; 10-Bella Dura; 11-Boreal; 12-Catarina; 13-Crioula Roxa; 14Crioula Branca; 15-Gauchinha

No primeiro grupo estão os genótipos Super Superprecoce e Gauchinha, sendo a Super Superprecoce uma população selecionada e mantida pela Epagri e a Gauchinha uma população comercial da empresa Hortec. O segundo grupo engloba a maioria dos genótipos estudados. Neste grupo todos os genótipos apresentam coloração da casca de cor amarelada, à exceção do genótipo Crioula Branca que é uma população mantida pela Epagri, mas que não se sabe ao certo sua origem. Este genótipo apresenta coloração da casca de cor branca, ciclo precoce e baixa capacidade de armazenamento. Já os genótipos Bella 
Figura 2 - Dendrograma obtido pelo método de agrupamento UPGMA e utilizando o coeficiente de similaridade de Jaccard. Os valores no dendrograma indicam os valores de "Bootstrap" correspondentes a cada agrupamento, em percentagem

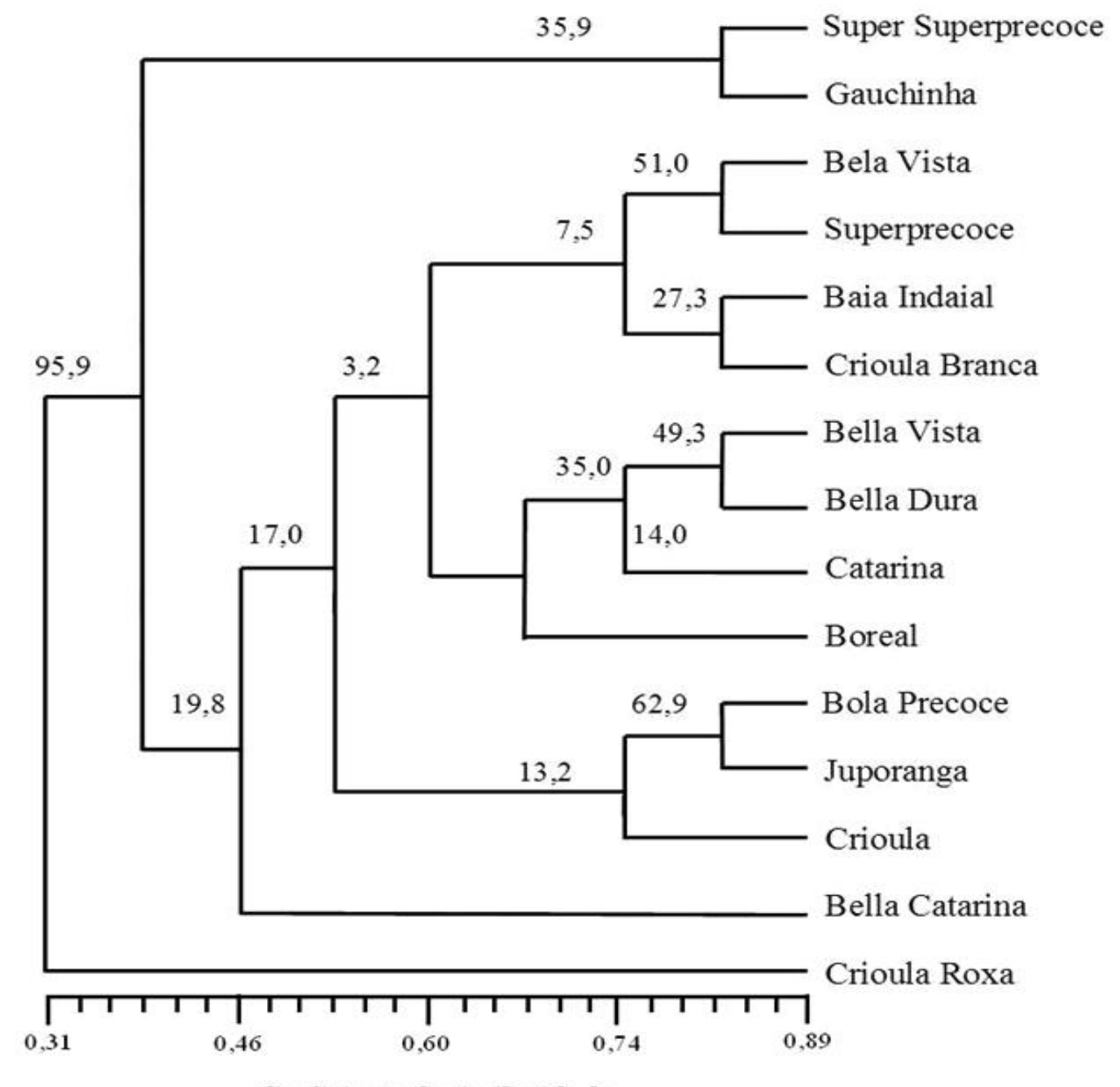

Coeficiente de similaridade

Vista (9) e Bella Dura (10) foram os que agruparam mais próximos, com 0,89 de similaridade. São híbridos que pertencem à empresa Sakata e que apresentam características fenotípicas semelhantes com pequenas variações no ciclo vegetativo e no formato. Também agruparam próximos, Bela Vista (2) e Superprecoce (3), com 0,88 de similaridade. Superprecoce tem sua origem em quatro populações precoces originadas da cultivar Baia Periforme, sendo que foram feitas seleções anuais das plantas que apresentaram precocidade e os bulbos selecionados foram recombinados em campos isolados de polinização aberta (GANDIN et al., 1998). Já o genótipo Bela Vista foi selecionado no município de Ituporanga, SC sendo mantido pela Epagri e podendo ser lançada como uma variedade comercial.
Finalmente, o genótipo Crioula Roxa foi o que apresentou o menor índice de similaridade com relação aos demais apresentando o valor de 0,31. De modo semelhante, os autores Barbieri et al. (2005) utilizando marcadores morfológicos também agruparam o genótipo Crioula Roxa emum grupo separadodos demais, sendo que a cor da casca foi a característica que mais contribuiu para a divergência entre os genótipos. Em trabalho com a utilização de marcadores RAPD, os genótipos Crioula Roxa, Bola Precoce e Crioula Alto Vale foram agrupados com uma similaridade superior a 70\% (LEITE; ANTHONISEN, 2009). Outros autores estudando a caracterização de genótipos de cebola quanto ao flavonóide quercetina, verificaram que o genótipo Crioula Roxa apresentou teores mais elevados deste flavonóide, em relação aos demais genótipos (LEITE et al., 2009). 
Alguns genótipos apresentam menor similaridade, ou seja, com maior divergência genética, como é o caso do genótipo Crioula Roxa $(0,31)$ e Super Superprecoce $(0,54)$ que podem ser utilizados em cruzamentos com os demais genótipos, buscando obter populações com maior variabilidade, permitindo a seleção de "tipos" com interesse agronômico. Deve-se observar que bulbos de cor rósea, resultantes da redução da 'anthocyanidin synthase' (ANS), são indesejados em cultivares de cebola, derivadas de cruzamentos entre cebola de bulbos vermelhos $\mathrm{x}$ bulbos amarelos principalmente (DINIZ et al., 2010). Sugere-se então o cruzamento entre os genótipos dos grupos um e dois, por exemplo, Juporanga x Super Superprecoce, Crioula Alto Vale x Gauchinha e Bela Vista x Gauchinha, visando à produção de novas combinações gênicas favoráveis.

\section{CONCLUSÕES}

A utilização de marcadores RAPD foi suficientemente informativa para avaliar diversidade genética entre os genótipos de cebola utilizados em Santa Catarina, demonstrando que existe variabilidade entre os mesmos.

\section{AGRADECIMENTOS}

À UDESC, CNPq, CAPES e FAPESC pelo financiamento da pesquisa, à Embrapa pela concessão de bolsa de estudo ao primeiro autor e à Epagri por liberar o primeiro autor para a pós-graduação.

\section{REFERÊNCIAS}

AREIAS, R. G. B. M. et al. Similaridade genética de variedades crioulas de arroz, em função da morfologia, marcadores RAPD e acúmulo de proteínas nos grãos. Bragantia, v. 65, n. 1, p. 19-28, 2006.

BARBIERI, R. L. et al. Divergência genética entre populações de cebola com base em marcadores morfológicos. Ciência Rural, v. 35, n. 2, p. 303-308, 2005.

BINNECK, E.; NEDEL, J. L.; DELLAGOSTIN, O. Análise de RAPD na identificação de cultivares: uma metodologia útil? Revista Brasileira de Sementes, v. 24, n. 1, p. 183-196, 2002.

BOITEUX, L. S.; MELO, P. C. T. Taxonomia e origem. In: OLIVEIRA, V. R.; BOITEUX, L. S. Sistema de produção de cebola (Allium cepa L.) Brasília. 5. ed. Embrapa Hortaliças: Embrapa-CNPH, 2004. Versão Eletrônica.

BORGES, W. L. et al., Variabilidade genética entre acessos de amendoim. Pesquisa Agropecuária Brasileira. v. 42, n. 8, p. 1151-1157, 2007.
BUZAR, A. G. R.; OLIVEIRA, V. R.; BOITEUX, L. S. Estimativa da diversidade genética de germoplasma de cebola via descritores morfológicos, agronômicos e bioquímicos. Horticultura Brasileira, v. 25, n. 4, p. 527-532, 2007.

CARVALHO, M. F. et al. Caracterização da diversidade genética entre acessos crioulos de feijão (Phaseolus vulgaris L.) coletados em Santa Catarina por marcadores RAPD. Ciência Rural, v. 38, n. 6, p. 1522-1528, 2008.

CARVALHO, A. O. R.; VIEIRA, L. G. E. Determinação das condições ótimas para análises de PCR-RAPD em Atta sexdens rubropilosa Forel (Hymenoptera: Formicidae). Neotropical Entomology, v. 30, n. 4, p. 593-600, 2001.

DIAS, L. A. S. Análises multidimensionais. In: ALFENAS, A. C. Eletroforese e marcadores bioquímicos em plantas e microorganismos. 2. ed. Viçosa: Ed. UFV, 2006. cap. 9, p. $405-475$.

DIAS, L. A. S. et al. Genetic distance and its association with heterosis in cacao. Brazilian Archives of Biology and Technology, v. 46, n. 3, p. 339-348, 2003.

DINIZ, L. S. et al. Identificação molecular de alelos para cor rósea em cultivares de cebola no vale do São Francisco. Horticultura Brasileira, v. 28, n. 2, 2010.

FERREIRA, M. E.; GRATTAPAGLIA, D. Introdução ao uso de marcadores moleculares em análise genética. 3. ed. Brasília: Embrapa-Cenargen, 1998. 220 p.

GANDIN, C. L. et al. Novas cultivares de cebola para Santa Catarina. Revista Agropecuária Catarinense, v. 11, n. 1, p. 5-7, 1998 .

LEITE, D. L. Melhoramento genético de cebola. In: BARBIERI, R. L. Cebola: ciência, arte e história. 2. ed. Brasília, DF: Embrapa Informação Tecnológica, 2007. cap.7, p. 77-113.

LEITE, D. L.; ANTHONISEN, D. Caracterização molecular de cultivares de cebola por marcadores RAPD. Horticultura Brasileira, v. 27, n. 4, p. 420-424, 2009.

LEITE, D. L. et al. Melhoramento genético de cebola para as condições tropicais e subtropicais do Brasil. Revista Colombiana de Ciências Hortícolas, v.3, n. 1, p. 18-27, 2009.

MAHAJAN, V. et al. Genetic fingerprinting of onion cultivars using SSR markers. Indian Journal of Horticulture, v. 18, n. 66 , p. $62-68,2009$

MANIRUZZAMAN, M. et al. Molecular characterization of onion (Allium cepa) using RAPD markers. Bangladesh Journal of Agriculturaal Research, v. 35, n. 2, p. 313-322, 2010 .

PHILLIPS, N. C. et al. Detection of genetic variation in wild populations of three Allium species using amplified fragment length polymorphisms. HortScience, v. 43, n. 3, p. 637-646, 2008.

RAMAlHO, M. A. P.; SANTOS, J. B.; PINTO, C. A. B. Genética na Agropecuária. 4. ed. Lavras: Lavras, 2008. 464 p. 
ROHLF, F. J. NTSYS-pc: numerical taxonomy and multivariate analysis system, version 2.1. New York: Exeter Software, 2000.

SANTOS, C. A. F. et al. Caracterização molecular de cultivares de cebola com marcadores microssatélites. Pesquisa Agropecuária Brasileira, v. 45, n. 1, p. 49-55, 2010.

SANTOS, C. A. F. et al. Similaridade genética entre cultivares de cebola de diferentes tipos e origens, baseada em marcadores AFLP. Horticultura Brasileira. v. 29, n. 1, p. 32-37, 2011.
VIEIRA, R. L.; NODARI, R. O. Diversidade genética de cultivares de alho avaliada por marcadores RAPD. Ciência Rural, v. 37, n. 1, p. 51-57, 2007.

VILELA, N. J. et al. Desafios e oportunidades para o agronegócio da cebola no Brasil. Horticultura Brasileira, v. 23, n. 4, p. 1029-1033, 2005.

YAP, I. V.; NELSON, R. J. Winboot: a program for performing bootstrap analysis of binary data to determine the confidence limits of UPGMA-based dendrograms. Manila: IRRI, 1996. $22 \mathrm{p}$. 